\title{
Anatomic Rim
}

National Cancer Institute

\section{Source}

National Cancer Institute. Anatomic Rim. NCI Thesaurus. Code C73991.

The border, edge, or margin of an organ or a part. 